\title{
EFFICIENCY OF RICE PRODUCTION AND ISSUES RELATING TO COST OF PRODUCTION IN THE DISTRICTS OF ANURADHAPURA AND POLONNARUWA
}

\author{
S.THIRUCHELVAM \\ Department of Agricultural Economics and Business Management, Faculty of Agriculture, University of Peradeniya, \\ Peradeniya.
}

(Accepted: 03 October 2005)

\begin{abstract}
Sri Lanka maintains a high level of self-sufficiency in rice at a cost to the economy. There is an issue of how to produce low cost rice and at the same time maintain comparative advantage in rice production of Sri Lanka. Hence, this study is focussed on the efficiency issues relating to productivity and the potential to reduce cost of production in paddy in the Anuradhapura and the Polonnaruwa districts. The analysis of secondary data revealed that there was an increment in the production and productivity of rice from 1995 to 2000 in the two districts. However, the nominal cost of production was increasing over time. The primary data (2001/ 2002) analysis indicates that more than half the farmers had less than the average yield level ( $5 \mathrm{mt} / \mathrm{ha}$.). About $16 \%$ and $21 \%$ of the farmers were performing well in the districts of Anuradhapura and Polonnaruwa respectively, with a productivity efficiency of over $90 \%$. There was a significant variation in cost of production between the districts, and within the districts. This indicates there are management problems and hence the need for training. Size of farm in relation to production efficiency indicates the need for larger holdings ( $>1 \mathrm{ha}$ ) for efficient use of resources, as reflected in Polonnaruwa. Small land holdings, high post harvest losses, low output quality and high cost of production and poor participation in farmer organization activities had a significant influence on the productivity efficiency among the low performing farmers in both districts.
\end{abstract}

Key Words: Cost of production, paddy, productivity efficiency, Sri Lanka

\section{INTRODUCTION}

The agriculture sector has continued to play a leading role in the economy of Sri Lanka. Average contribution of this sector to Gross Domestic Product (GDP) was 19\% in 2003. Paddy production during the 2003 cultivation year reached an all time high level of 3,071 thousand metric tons. Paddy production independently contributed 7.1 $\%$ of the total GDP in 2003. ${ }^{1}$ Total area under paddy cultivation has been about 817,000 ha during the last two decades. Paddy cultivation employs 1.8 million farmers, of whom over $67.3 \%$ cultivate less than 0.8 ha each. ${ }^{2}$ Though declining, the agricultural sector still absorbs $32 \%$ of the labour force in the country. ${ }^{3}$ However many of the farmers are either directly or indirectly engaged in paddy cultivation. During the past decade, selfsufficiency ratio has varied between $85 \%-98 \%$. This is mainly due to an increase in the area under cultivation and also increase in yield per hectare. Demand for rice is steadily increasing due to the increase in population at the rate of approximately $1.2 \%$ annually. ${ }^{4}$ The total amount of rice needed in the years 2005, 2010 and 2020 are estimated at $3.23,3.46$ and 3.83 million metric tons respectively.

Pevious studies ${ }^{5,6}$ on the comparative advantage of paddy production highlighted that it is cheaper for Sri Lanka to import than produce rice in the less productive areas. The low competitiveness shows that Sri Lanka's rice sector is characterized by high cost of production and low yields. The analysis of secondary data shows that about $50 \%$ of the total annual production comes from four major rice producing districts Ampara, Polonnaruwa, Kurunegala and Anuradhapura. There was an increase in the paddy production in these districts form 1995 to 2000. The secondary data analysis also indicates a fall in real price of paddy, an increase in wage rates and an increase in nominal cost of production over time. Therefore, while searching for means to cultivate rice at a lesser cost, an increase in yield is imperative to reduce cost of rice production. The future of food security in Sri Lanka will depend on the ability to improve paddy productivity and profitability on an economically sustainable basis.

The present study was undertaken with the general objectives of investigating the productivity efficiency, identifying factors affecting cost of production and finding means to reduce cost of production while increasing the paddy production in the Anuradhapura and the Polonnaruwa Districts. 


\section{METHODS AND MATERIALS}

The study covered two North Cenral Province districts in the Dry Zone namely Anuradhapura and Polonnaruwa. The area of the study was based on the irrigated regime. The study sites selected in the Anuradhapura District were located in the Eppawella block in the Mahaweli System $\mathrm{H}$ in Rajangana, along the right bank channel and in Elayapathuwa minor tank scheme. In the Polonnaruwa District, Ellewawe block in the Mahaweli System B, Nuwaragala block in the Mahaweli System C and two Agricultural Divisions in Parakrama Samudraya irrigation schemes were selected for the study.

Multiphase sampling was adopted in this study. In probability sampling, areas along two distributory channels were selected first to represent the problem and then four areas along each distributory channel were randomly selected. Farmers from each area were stratified based on head and tail end of the channel and five farmers were randomly selected. In each study site, not less than 50 farmers were selected. Thus a total of 300 farmers were randomly selected from the two study districts. Further, a focus group discussion and informal discussions with key persons were carried out to collect the information on institutional aspects.

Primary data regarding input use in paddy production for Maha cultivation 2000/2001 and Yala cultivation 2002, farmers' household information, assets level, farmers' debt levels, and participation in farmer organization activities, were collected through the field survey carried out during September to December 2001 in the study areas.

First, the study assesses the yield gaps. The information on yield in research plots in each locality was compared with the average yield achieved by the well performing farmers (Yield Gap I) and the average yield of all farmers in the same location (Yield Gap II). Further a yield gap (Yield Gap III) based on the yields experienced by the low performing farmers was also computed.
Secondly, this study employed the frontier method as an analytical tool to examine the productivity efficiency of paddy farms. Several methods have been developed to determine the most efficient production frontier by different researchers. ${ }^{7-9}$ Technical efficiency in particular, examines the input use in the production side, and is independent from the cost associated with production. However under certain economic conditions, farmers take decisions based on price. Thus technical efficiency is not based on purely technical decisions alone but is based on economic judgement as well. Despite its well-known limitations, the Cobb-Douglas functional form has been widely used in farm efficiency analysis for both developing and developed countries. Previous studies ${ }^{10,11}$ estimated both deterministic and stochastic frontier production of Cobb-Douglas type for rice and other field crops in the Mahaweli System H. incorporated socio economic factors directly in the production frontier model and showed that owner farmers performed better than tenant farmers. In this study all parameters were estimated in a single stage Maximum Likelihood Estimate (MLE) procedure as in the computer software-FRONTIER version 4.1.13 The model was derived by, first, fitting Ordinary Least Square (OLS) models experimentally before estimating by the maximum likelihood methods. The estimated production function was of the form:

$\operatorname{Ln}\left(\mathrm{Y}_{\mathrm{i}}\right)=\Sigma \beta_{\mathrm{j}} \ln \left(\mathrm{X}_{\mathrm{ij}}\right)+\mathrm{v}_{\mathrm{i}}-\mathrm{u}_{\mathrm{i}}+\Sigma \beta_{\mathrm{j}} \mathrm{Z}_{\mathrm{j}}$

Where $\mathrm{Y}_{i}$ is (the logarithm of) kilograms of production produced by the $i^{\text {th }}$ farmer, $X_{i j}$ are the vectors of (the logarithm of) inputs used by the $i^{\text {th }}$ farmer, such as land area under paddy in acres, labour in man days, cost of seed, cost of agrochemicals and cost of machinery; $\mathrm{Zj}$ are variables which may influence the efficiency of the farm, such as farming experience, part time farming, asset level and membership in farmer organizations. Finally to investigate the cost of production, gross marginal analysis and tabulation analysis were used. Based on the productivity efficiency, farmers were categorized into three classes such as efficient, average and low performing farmers. The costs of production and input use were compared. 


\section{RESULTS}

\section{Socio-economic conditions of farmers}

The information on age of farmers indicates that they are in their active age (less than 55 years) in both districts. A high percentage (75\%) of farmers in the Mahaweli Systems H, B and C have received secondary education and this indicates that they have the knowledge to understand the correct farming techniques. On an average, in both districts the majority of the farmers have experience of farming for more than 25 years. About $85 \%$ of the farmers in Mahawali Systems $\mathrm{H}, \mathrm{B}$, and $\mathrm{C}$ were full time farmers. Around minor tanks and in old schemes part time farming is as high as $39 \%$. The average family size is higher (6.8) in Polonnaruwa than in Anuradhapura (5.6). More than $90 \%$ of the farmers interviewed in the major schemes in Anuradhapura and Polonnaruwa are owner cultivators. In contrast, $62 \%$ of owner cultivators points to an apparent tenancy problem in the minor tank areas.

\section{Yield gap}

Yield gap I and Yield gap II calculated using the survey data show that, despite the availability of new improved varieties with a potential yield of little above $8 \mathrm{mt} / \mathrm{ha}$ as maximum realized average yield, the actual level has been around $5.01 \mathrm{mt} /$ ha and $4.4 \mathrm{mt} / \mathrm{ha}$ in the Anuradhapura and Polonnaruwa districts respectively. There is a big yield gap between actual yield and the potential yield (Yield gap II) in all the study areas. The average current yield in System $\mathrm{H}$ for paddy in Maha is $5 \mathrm{mt} / \mathrm{ha}$ and in Yala is $4.4 \mathrm{mt} / \mathrm{ha}$. However their potential yields could be $6.5 \mathrm{mt} / \mathrm{ha}$ and 5.4 $\mathrm{mt} / \mathrm{ha}$ in Maha and Yala seasons respectively.

\section{Paddy productivity and input use}

Table 1 shows that the extent of cultivation in the Polonnaruwa district (1.05-1.28 ha) is higher than that of in the Anuradhapura District (1.0 ha). The yield is higher in Mahawali System H (4579 $\mathrm{kg} / \mathrm{ha}$ ) than in Rajanganaya $(4,204 \mathrm{~kg} / \mathrm{ha})$ and in the minor irrigation schemes $(3,599 \mathrm{~kg} / \mathrm{ha})$. In both districts, the yield of Maha $(4,320 \mathrm{~kg} / \mathrm{ha})$ is

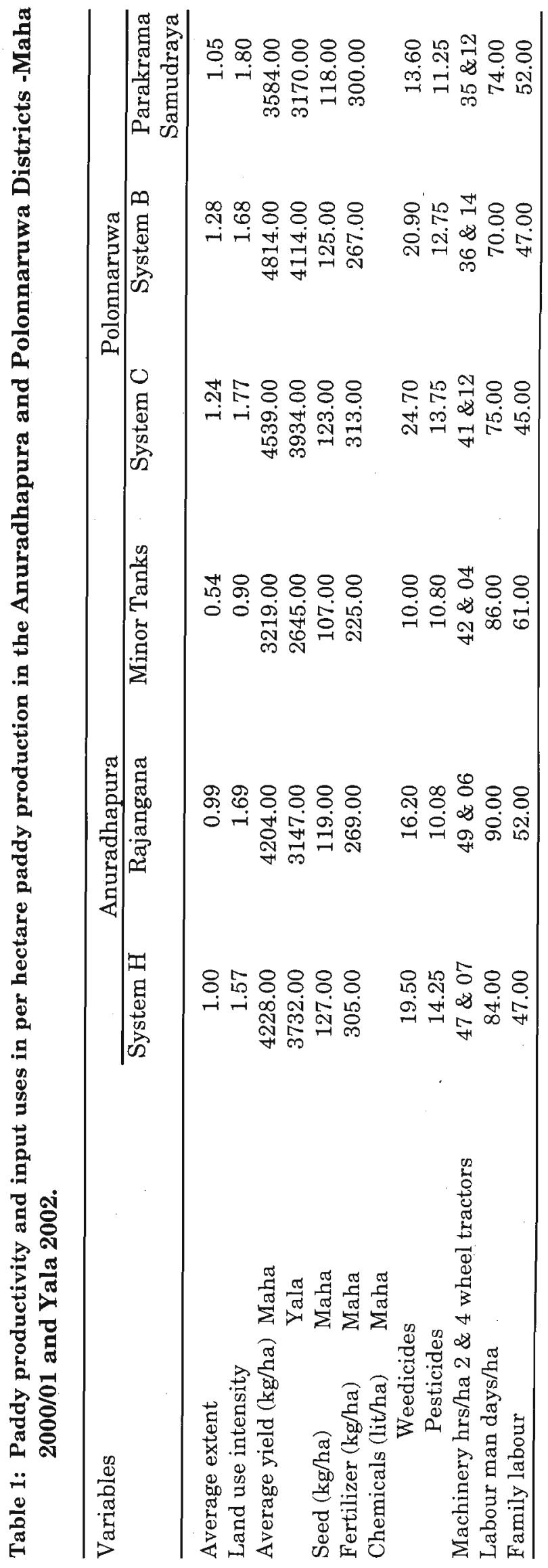


higher than that of Yala (4080 kg/ha). The land use intensity in Polonnaruwa is higher (1.8) than that of in Anuradhapura (1.6) and in Elayapatuwa minor tank area (0.9).

The Maximum Likelihood estimates for the parameters for stochastic frontier and the inefficiency model for Anuradhapura major irrigation scheme, Elayapattuwa minor tanks areas and Polonnaruwa major irrigation schemes are shown in Table 2. Causes of inefficiency in farms were determined with the production frontier in a single stage maximum likelihood estimate. These results are also presented in Table 2.

\section{Factors affecting cost of production}

The difference between productivity and cost of production in the efficient and less efficient farmer categories in the Anuradhapura and Polonnaruwa districts were calculated for major and minor tank irrigation systems and are presented in Table 3.

\section{DISCUSSION AND CONCLUSION}

Socio-economic conditions of farmers: The analysis of socio-economic conditions of farmers indicates that with increase of family size and years of farming experience, more farmers in the minor tank areas and in old schemes are becoming

Table 2: Maximum likelihood estimates for parameters of stochastic frontier production function and inefficiency function in the Anuradhapura and Polonnaruwa Districts. Pooled paddy production data Maha 2000/01.

\begin{tabular}{|c|c|c|c|}
\hline \multirow[t]{2}{*}{ Variables } & \multicolumn{2}{|c|}{ Anuradhapura } & Polonnaruwa \\
\hline & $\begin{array}{c}\text { Mahaweli Sys. H } \\
\text { \& Rajangana } \\
(n=100) \\
\text { Coefficient }\end{array}$ & $\begin{array}{c}\text { Elayapathuwa } \\
\text { Minor Tanks } \\
(\mathrm{n}=50) \\
\text { Coefficient }\end{array}$ & $\begin{array}{c}\text { Mahawali Sys. B, C \& } \\
\text { Parakrama Samudraya } \\
(\mathrm{n}=150) \\
\text { Coefficient }\end{array}$ \\
\hline
\end{tabular}

\section{Stochastic frontier}

Intercept

Land (ac.)

Labour (man days)

Power (Rs.)

Agrochemicals (Rs.)

Seeds (Rs.)

Inefficiency effects

Ownership

Farming category dummy

Age (years)

Debt level dummy

F.O participation

Sigma squared, $\sigma^{2}{ }_{s}$

Gama, $\gamma^{2}=\sigma_{\mathrm{s}}^{2} / \sigma^{2}$

Log likelihood (LLF)

\section{$\beta$}

$\begin{array}{lcl}3.891^{* *} & 0.696 & 6.553^{* * *} \\ 0.418^{* * *} & 0.265^{*} & 0.651^{* * *} \\ 0.0991^{*} & -0.119 & 0.054 \\ -0.995 & 0.095 & 0.103^{*} \\ -0.191^{* *} & 0.198 & -0.117^{*} \\ 0.066 & -0.265^{*} & -0.041\end{array}$

$\delta$
$-1.341^{* *}$
0.931
$-0.231^{* *}$
0.185
$-0.135$
0.243
0.361
0.146
-0.257 *
$0.296^{* *}$
$-0.346^{*}$
$1.035^{* *}$
$-0.444^{*}$
0.153 *
$-0.372^{*}$
$0.228^{* * * *}$
0.346
$0.103^{* * *}$
$0.832 * * *$
$0.911^{* * * *}$
$0.873^{* * *}$
25.434
16.406

*** Significant at $1 \%$ level

** Significant at $5 \%$ level

* Significant at $10 \%$ level 


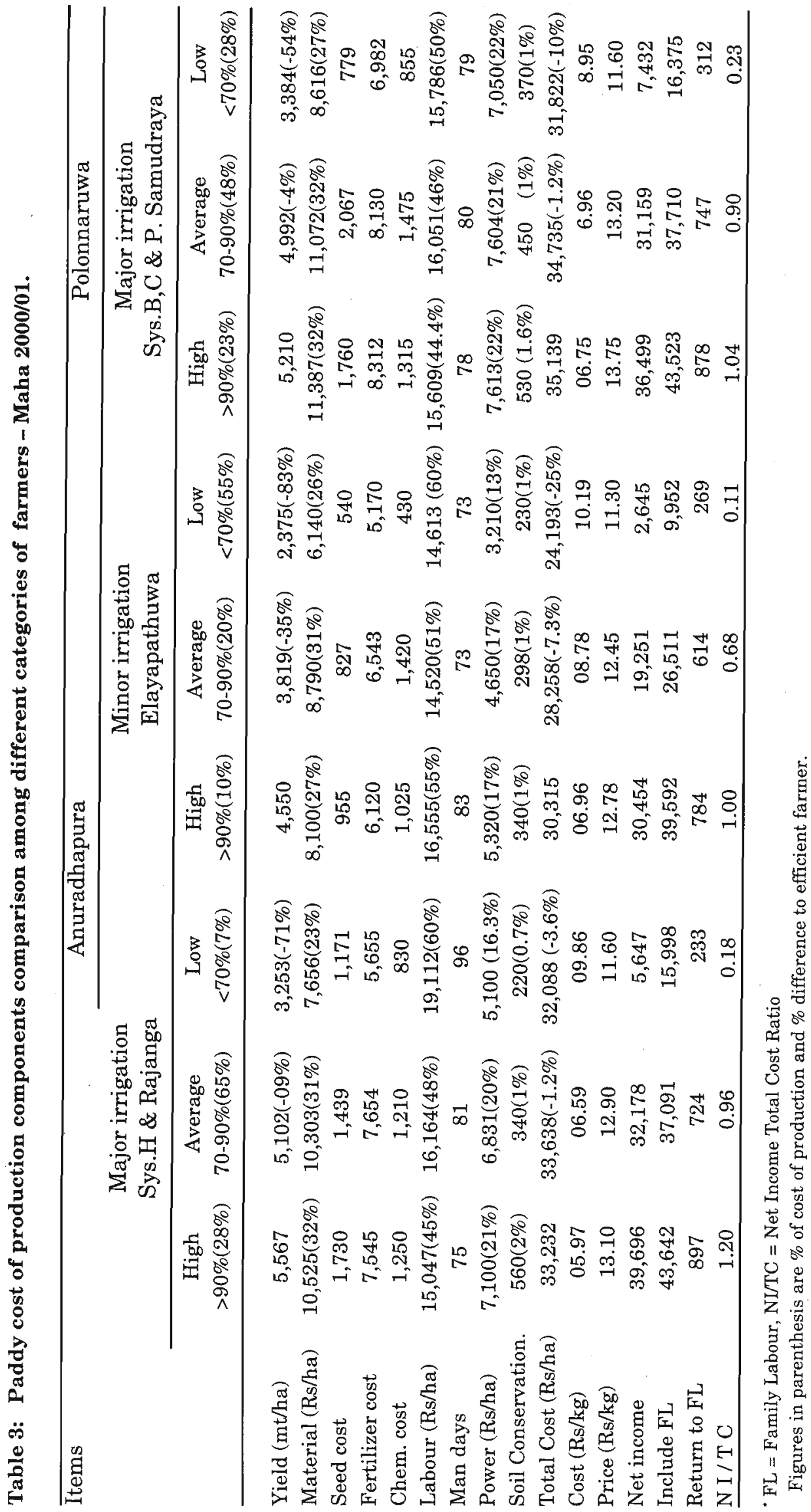


part time farmers. Low percentage of ownership and higher level of part time farming in minor tank areas indicate loss of productivity of land in the long run. Land ownership investigation highlights an apparent tenancy problem in the minor tank areas and the existence of hidden tenancy in the Mahaweli systems.

Yield gap: The yield gap analysis reveals that there is a sizeable yield gap between achievable and actual yields in both districts and that there is potential for raising the yield level in the long term. It is evident from this study that technical knowledge is important in the adoption of improved practices for increased yields. Yield gap I is smaller than Yield gap II indicating little scope for increase through improved crop management. A higher Yield gap II indicates that existing technology could be exploited with improvement in the practices for further increase in rice production. For the low performing farmers, extension, credit and market information are needed. Farmers are not market oriented and have not realized their potential. The analysis of distributions of yield achievement in the Anuradhapura and the Polonnaruwa districts indicate that the majority (70\%) of the farmers in the study areas did not perform even upto the average level that could be achieved. The investigation has also revealed that there is more room for future increase of yield under current technology and economic conditions.

\section{Paddy productivity and input use:} Investigation of paddy productivity and input use in major tank areas in the Polonnaruwa and Anuradhapura districts indicate the advantages of economies of scale. The average yield per hectare in major irrigation areas during Maha $2000 / 01$ was $5.05 \mathrm{mt} / \mathrm{ha}$ and $4.44 \mathrm{mt} / \mathrm{ha}$ in the Anuradhapura and the Polonnaruwa districts respectively. The yields in major tank areas are significantly (29\%) higher than those in minor tank areas. The smaller yield gap between research yield and actual yield in both districts indicates the importance of further research to develop appropriate rice hybrids.

Land use intensities of $1.8,1.6$ and 0.9 in Pollonaruwa, Anuradhapura and Elayapatuwa minor tank areas respectively, reflect the degree of water scarcity problems. Seeding rate was higher in the major schemes than that of minor schemes. Seeding rate has been increasing, mainly because of gradual shift in crop establishment method from transplanting to broadcasting. In both districts over $95 \%$ of the rice area are cultivated with new varieties. It was found that farmers had developed a tendency to cultivate short duration varieties even when water is abundant.

Agrochemical use was less in minor tank areas than in major tank areas. The intensity of agrochemical use was higher in Polonnaruwa than in Anuradhapura. Polonnaruwa farmers perceived pests as the main limiting factor. The yield gap was attributed more to weeds than insects. The data show that labour use was higher in minor tank areas than in major tank areas. In Polonnaruwa there was less use of labour when compared to Anuradhapura. There was a shortage of labour in both districts, due to youth moving away from agriculture for more attractive and higher wage earning non-farming occupations.

In Table 2 the values of the likelihood ratios indicate that the models had a good fit and that inefficiency effects of a stochastic nature exist. The estimated parameters of the production function confirm with prior expectation. In the Anuradhapura and the Polonnaruwa districts, the models showed significant impact of land, power and labour on paddy production in that order. Out of six variables tested, only land was significant in both minor and major tank areas. The higher land elasticity suggests that output could be increased by a larger proportion through better soil conservation and land saving technology. In Polonnaruwa, the higher land input elasticity of 0.651 shows that output could be increased by a lager proportion through land consolidation and soil conservation. In the Elayapattuwa minor tank area, land had low positive significant effect while seed and labour had significant negative impact on paddy production. These reveal the problems of under utilization of land, over use of labour and use of low quality seed paddy in the minor tank areas. According to the results, land and labour show significant effect on paddy production in the 
major schemes in Anuradhapura. Power was significant in Polonnaruwa suggesting the use of tractors to increase production.

Overall results of the regression show the inefficient use of resources. In both districts, land showed significant effect on production while seed and agrochemical showed no effect on production. This indicates the importance of seed and fertilizer technology for improvement of land productivity in both districts. Labour and power were significant in both districts. The significant coefficient for power suggests that, labour productivity could be improved with machinery use in the Anuradhapura district.

\section{Productivity efficiencies of farmers: The} means and ranges of the estimated productivity/ technical efficiencies for the Anuradhapura district show that the estimated average technical efficiency for Mahaweli $\mathrm{H}$ area was $87 \%$. The technical efficiency levels of farmers varied between $41 \%$ and $98 \%$. The estimated mean technical efficiency of Rajanganaya was as high as Mahaweli $\mathrm{H}$ area, but the variability was less. Rajanganaya, had a $22 \%$ higher technical efficiency than the minor tank areas in Elayapathuwa. The calculated mean technical efficiency for paddy production in the Anuradhapura district was $77 \%$. Technical efficiency levels of the farmers varied between $24 \%$ and $98 \%$. These data show the existence of vast differences of production efficiency of farmers although they operate under similar conditions and face the same cost of production. Further, the investigation evidenced that larger farms were much more likely to appear efficient than small ones.

Based on the mean of technical efficiency, farmers were categorized into three groups: 1. Low $(<70 \% \mathrm{TE}), 2$. Average ( $>71 \% \mathrm{TE}<90 \%), 3$. High $(>91 \% \mathrm{TE})$. A closer look into the categories of farmers showed that $15 \%$ and $55 \%$ of the farmers had low technical efficiency in Rajanganaya and minor tank areas respectively. In the Anuradhapura district efficient farmers who had technical efficiency above $90 \%$ were higher (28\%) in major schemes and it was only $10 \%$ in minor schemes in Anuradhapura. In Polonnaruwa efficient farmers were about $23 \%$. This was due to lower performance of Parakarama Samudraya area which had $9 \%$ of efficient farmers. Loosing profit, high cost of production, less institutional facilities than Mahaweli areas were the reasons for this situation.

Factors affecting productivity efficiency: In the inefficiency model, out of the five variables except age, the other factors such as farming category, farmer participation in farmer organization, debt level and distance from branch irrigation channel were significant. The significant negative indication was found in farmer participation. This means that more participation in farmer organization activities would reduce technical inefficiency. There was a positive and significant contribution to inefficiency for other variables. Age of farmers was positive. This indicates that older farmers contribute to inefficient farming when compared to young farmers.

Non-significance of farming category indicates that prevalence of part- time farming had no effect on paddy farming and it allows more time for off farm employment. The increase of distance between the land and the distributory irrigation channel contributes to more inefficiency. This is indicated by its positive significant coefficient. Increasing chemical cost and machinery cost also increases the output efficiency.

The results suggest that rich farmers are efficient in the major irrigation schemes but not in the minor irrigation schemes. Membership in farmer organizations is the key variable that improves the technical efficiency. This was evident in both study areas. Reduction of inefficiency with participation in farmer organization activities was shown with higher and negative significance levels in the Rajanganaya and in Elayapathuwa areas. Further, it was evident that the part-time farmers were associated with higher levels of inefficiency in both study areas. The other variables such as education and experience in farming did not affect the variation in farm efficiency significantly.

Factors affecting cost of production: Comparison of the yield levels of the low performing farmers with average performing 
farmers highlights that there is about $50 \%$ variation in the major tank areas. There was much variation in cost of production between the efficient and low performing farmers. The variation of cost of production in Maha 2000/01 in major irrigation schemes ranged from $\mathrm{Rs} 32,088$ to $\mathrm{Rs}_{\mathrm{s}} 33,638$ and from $\mathrm{Rs} 31,822$ to Rs 35,139 per hectare in the Anuradhapura and the Polonnaruwa districts respectively. In minor tank areas, the cost ranged between $\mathrm{Rs}_{\mathrm{s}} 24,193$ and $\mathrm{Rs}_{\mathrm{s}}$ 30,315 per hectare. The cost was lower in minor tank areas than in major tank areas. Among the major tank areas, cost was higher in Polonnaruwa than in Anuradhapura. Significant difference between the yields of efficient and inefficient farmers incurring the same cost of production, indicates the potential for significant $(20 \%-30 \%)$ increase in production by a majority $(40 \%-60 \%)$ of the low performing farmers with reduction in cost of production. The study evidenced the rising cost of production in which labour cost accounts for $44 \%$ to $60 \%$ of the total cost of production.

The analysis of cost of production confirms the notion that higher input use could lead to higher productivity resulting from positive interactions among inputs especially when they are of improved quality. There was, significant difference in per kilo cost of production between the different categories of farmers and districts. The variation in per kilo cost of production between average farmers in Anuradhapura and Polonnaruwa were $\mathrm{Rs} 6 / \mathrm{kg}$ and $\mathrm{Rs} 7 / \mathrm{kg}$ respectively. In minor tank areas it was $\mathrm{Rs} 12.45 /$ $\mathrm{kg}$. The cost of production of efficient farmers was almost equal to the market price.

The return for family labour for the efficient farmers were $R_{s} 1,584 /$ man day, $R_{s} 784 /$ man day Rs 897/man day and $\operatorname{Rs}_{\mathrm{s}} 878 / \mathrm{man}$ day in minor tank areas and major tank areas in the Anuradhapura and the Polonnaruwa districts respectively. These results indicate that paddy generates about 3.5, 2.6 and 1.04 folds more than average wage rate of $\mathrm{Rs} 250 / \mathrm{man}$ day, among the efficient, average and low efficient farmers respectively.

The net return to total cost ratios explains that efficient farmers were well off with ratios higher than one. The average performing farmers who had ratios close to one, managed to get reasonable profit. In the case of poor performing farmers it was not profitable for them to produce paddy, as their production was not even at break even level. The results reveal that paddy cultivation seems to be unprofitable in minor tank areas. However majority of the farmers in the minor tank areas cultivates paddy mainly for consumption purposes.

The study shows that there was significant variation in the achieved yield by the different efficient categories of farmers. Poor stand establishment, imperfect weed control, inadequate and imbalanced fertilizer application, negligence in pest and disease control, delayed harvesting and ignorance in post harvest operations were found to lead to a substantial crop loss among the poor performing farmers in both districts. Evidence indicates that, technical knowledge is important in determining the adoption of improved practices and obtaining increased yields. Over $70 \%$ of the farmers indicated that yields were less than expected. The reasons in the order of importance were the problems relating to water, insect, fertilizer and delayed planting. There is room for future increase of yield under current technology and economic conditions. The analysis showed an opposite picture on the cost of production, where there was no significant difference among them. The average share of material, labour and power in the total cost of production was $30 \%, 50 \%$ and $20 \%$ respectively. It was clear that, there was a higher labour share and lower material and power share among low performing farmer category than the efficient farmers in both districts. This was due to a significant difference in the inputs used by them. Efficient farmers obtained a yield of $5.1 \mathrm{mt} /$ ha and least efficient farmers' yield was $3.3 \mathrm{mt} / \mathrm{ha}$. This gap can be reduced without increasing the cost of production.

It was revealed by the farmers' interview that high post harvest loses $(20-30 \%)$ are mainly due to the scarcity of labour during the harvesting seasons. The main credit source was the local merchant who supplies the inputs for paddy production and consumer goods on credit. At the 
time of harvest, farmers were compelled to sell the paddy to the merchant where he charged $30 \%$ interest and bought the product at the harvesting time when the price was low. Extension services in both districts were not satisfactory according to farmers' perception.

Following recommendations were derived from the above findings:

1. Since the majority of farmers are cultivating their own land and most of them are full-time farmers, long term measures to improve land productivity such as soil fertility management and soil conservation practices can be introduced effectively.

2. The use of family labour and mechanization of harvesting can reduce the cost of production substantially.

3. Since majority of the farmers operate on less than one hectare, they do not have a opportunity to achieve economies of scale. This can be achieved by integrating small farmers in to systems. The organizational system can be developed as farmers' cooperatives, farmer companies or contract farming. Further, it is time to review the present tenurial legislation in order to find an alternative solution to fragmentation of agricultural land.

4. Better extension services should be provided to farmers because, they are unaware of proper fertilizer and agrochemical use and soil management practices.

5. Farmer organizations should be strengthened in order to encourage farmer group action and farmer co-operation in respect of marketing, credit, input use and organizing cultivation.

6. Private institutions were mainly involved in the paddy marketing activity. Participation of Government institutions in the paddy marketing is very important to establish a better price.

\section{Acknowledgement}

The author is thankful to the National Science Foundation, Colombo for Financial support.

\section{References}

1. Central Bank of Sri Lanka (2003). Annual Report, CB, Colombo.

2. Department of Census and Statistics. (1982). Sri Lanka Census of Agricultural, General Report. Department of Census and Statistics, Colombo.

3. Central Bank of Sri Lanka (2003). Annual Report, CB, Colombo.

4. Department of Census and Statistics (2001). Paddy statistics 2000/2001 Maha, 5-11, Department of Census and Statistics, Colombo.

5. Kikuchi M.,Barker M.R., Samad M. \& Weligamage P. (2001). Comparative advantage of rice production in Sri Lanka with special reference to irrigation costs. Paper presented at Workshop on Medium and Long Term Prospects of Rice Supply and Demand in the $21^{\text {st }}$ Century. 3-5 December.

6. Rafeek M.I.M. \& Samaratunga P.A. (2000). Trade liberalization and its impact on the rice sector of Sri Lanka. Sri Lankan Journal of Agricultural Economics 3: 143-154.

7. Farrel M.J. (1957). The measurement of production efficiency. Journal of the Royal Statistical Society, Series A 120:253-281.

8. Timmer C.F. (1971). Using a probabilistic frontier function to measure technical efficiency. Journal of Political Economy 79: 776-794.

9. Aigner D.J., Lovell C.A.K. \& Schmidt P. (1977). formulation and estimation of stochastic fontier production function models. Journal of Econometrics 6:21-27.

10. Ekanayake S.A.B. \& Jayasuriya S.K.W. (1987). Measurement of farm specific technical efficiency: A comparison of methods. Journal of Agricultural Economics 38: 115-22. 
11. Karunaratne M.A.K.H.S.S. \& Herath H. M.G. (1989). Efficiency of rice production under major irrigation conditions: A frontier production function approach. Tropical Agricultural Research 1: 142-158. 13.

12. Thiruchelvam S. \& Somaratne H.M. (2001). Impacts of Bethma Cultivation on Agricultural Productivity Efficiency: A Case Study of
Mahaweli System H Area. Proceedings of the Annual Research Session 2001. p. 10 November 21. University of Peradeniya.

13. Coelli T.J. (1994). A guide to frontier version 4.1: A Computer Programmer for Stochastic Frontier Production and Cost Function Estimation. Department of Economy, University of New England, Australia. 